\title{
Optical Imaging of SI Topography in Anesthetized and Awake Squirrel Monkeys
}

\author{
Li Min Chen, Robert Mark Friedman, and Anna Wang Roe \\ Department of Psychology, Vanderbilt University, Nashville, Tennessee 37203
}

Orderly topographic maps in the primary somatosensory cortex (SI) serve as an anchor for our understanding of somatosensory cortical organization. However, this view is mostly based on data collected in the anesthetized animal. Less is known about these topographies in the awake primate. Even less is known about the relative activations of different subdivisions of SI (areas 3a, 3b, 1, and 2). Toward the goal of understanding the functional activation of SI, we conducted intrinsic signal optical imaging of areas $3 \mathrm{~b}$ and 1 in awake squirrel monkeys. Monkeys were imaged repeatedly for a period of $>2$ years in awake and anesthetized states in response to vibrotactile and electrocutaneous stimuli presented to individual fingerpads. During this period, we found stable somatotopic maps in both the anesthetized and awake states, consistent with electrophysiologically recorded maps in areas $3 \mathrm{~b}$ and 1 in the anesthetized state. In the awake animal, signal sizes were larger, but variability was greater, leading to decreased signal-to-noise ratios. Topographic activations were larger (in both area and amplitude) in the awake animal, suggesting either a less precise topography and/or more complex integration. This brings into question the role of a precise topographic map during behavior. In addition, whereas in the anesthetized animal strongest imaging signals were obtained from area $3 \mathrm{~b}$, in the awake animal, area 1 activation dominated over that in area $3 \mathrm{~b}$. Differences in relative dominance of area $3 b$ versus area 1 suggest that inter-areal interactions in the alert animal differ substantially from that in the anesthetized animal.

Key words: optical imaging; awake; primate; somatosensory cortex; anesthesia; topography

\section{Introduction}

Orderly topographic sensory maps in the primary somatosensory cortex (SI) serve as an anchor for our understanding of somatosensory cortical organization (Woolsey et al., 1942; Nelson et al., 1980; Sur et al., 1982; Pons et al., 1985, 1987). This view is mostly based on data collected in the anesthetized animal. Little is known about these topographies in the awake primate (McKenna et al., 1982; Iwamura et al., 1993; Blankenburg et al., 2003). It is still a question whether the fundamental structure of topographic maps in SI in the anesthetized animal are the same as the functional maps explored in the awake behaving animal and whether topography remains stable over time in the awake animal or is dependent on behavioral context. The long-standing view that sensory topography in the somatosensory cortex reflects a "body map" is well supported. However, a recent study has called into question traditional views of somatosensory cortical maps (Chen et al., 2003). This study demonstrated that cortical activity maps the location of perceived tactile stimulation rather than the location of physical stimulation on the skin, thereby suggesting that

Received Jan. 11, 2005; revised July 7, 2005; accepted July 8, 2005.

This work was supported by National Institutes of Health Grant NS044375, the Packard Foundation, and a Brown-Coxe fellowship. Part of the data presented in this manuscript was collected in the Department of Neurobiology at Yale University (New Haven, CT). We thank Barbara Heider for assistance on initial experiments and Francine Healy for excellent technical assistance.

Correspondence should be addressed to Dr. Anna Wang Roe, Department of Psychology, Vanderbilt University College of Arts and Science, 301 Wilson Hall, 111 21st Avenue, Nashville, TN 37203. E-mail: anna.roe@ vanderbilt.edu.

DOI:10.1523/JNEUROSCI.1990-05.2005

Copyright $\odot 2005$ Society for Neuroscience $\quad$ 0270-6474/05/257648-12\$15.00/0 the topographic map in area $3 \mathrm{~b}$ is a perceptual map rather than a physical one. Given this view, it is possible that in the awake animal, cortical topography is established dynamically depending on perceptual or behavioral context (Wang et al., 1995).

Neither is much known regarding the relative activations of different cortical areas (within the primary somatosensory cortex of the primate, SI, are cortical areas $3 a, 3 b, 1$, and 2). Because different cortical areas are characterized by distinct stimulus preferences (Mountcastle and Powell, 1959; Hyvarinen and Poranen, 1978; Costanzo and Gardner, 1980; Carlson, 1981; Sur et al., 1985; Iwamura et al., 1993), it is possible that different cortical areas become dominant under changing stimulus and behavioral contexts. A number of studies have investigated behavioral modulation of neuronal response within single cortical areas (Iwamura et al., 1983; Nelson, 1987; Nelson et al., 1991; Hsiao et al., 1993; Burton and Sinclair, 2000; Meftah et al., 2002); however, little is known about the modulation of inter-areal dominance or of patterned area-specific functional organizations during behavior (Friston, 1998; Mesulam, 1998; Ungerleider et al., 1998). Indeed, what is the behavioral relevance of known functional organizations and topographies? Such studies would provide important constraints for studies on feedforward versus feedback influences in cortical processing.

Toward the goal of understanding the relationship of functional organizations, topography, and inter-areal activation during behavior, we have conducted intrinsic signal optical imaging of SI in awake squirrel monkeys in response to stimulation of single digits. The aim of this first study is to establish a baseline of 
imaged activity in the awake monkey, one that can be directly compared with that obtained in the same monkey in the anesthetized state. In this way, direct relationships can be made between functional activations in the anesthetized and awake states, with the aim of providing a view of how functional architectures are used in the awake state and ultimately the relevance of functional organizations in general.

\section{Materials and Methods}

Two adult male squirrel monkeys (Saimiri sciureus) were implanted with a chronic chamber and head post and trained to be quiescent in the primate chair. The monkeys were imaged both in anesthetized and awake conditions. Detailed surgical and optical imaging procedures have been described previously (Chen et al., 2001, 2002; Ramsden et al., 2001) and will be described briefly in the following sections. All procedures were conducted in accordance with National Institutes of Health guidelines and approved by Animal Care and Use Committees.

\section{Stimuli}

Vibrotactile or innocuous electrocutaneous stimuli were presented to the glabrous skin of distal fingerpads. In both awake and anesthetized states, identical vibrotactile and electrocutaneous stimuli were used. The vibrotactile stimulator consisted of a mini 3 VDC vibrator motor (Sanko Electric, Taichung, Taiwan) glued to the skin. This mini vibrator motor produced a $2.5 \mathrm{~Hz}$ train of five pulses (each pulse duration was $75 \mathrm{~ms}$ ) that evoked a perception of tapping. Electrocutaneous stimuli consisted of a $2.5 \mathrm{~Hz}$ train of five constant current DC pulses (each $2 \mathrm{~ms}$ in duration) of $3.5-5 \mathrm{~mA}$ amplitude. Current was provided by a GrassTelefactor S88 stimulator, stimulus isolation unit, and constant current units (Astro-Med, West Warwick, RI) through two ball electrodes ( $2 \mathrm{~mm}$ diameter separated by $5 \mathrm{~mm}$ ) glued to the distal fingerpad. Skin impedance between the two ball electrodes was measured before, during, and after imaging to confirm good skin contact. In some anesthetized experiments (see Fig. 2), we also used a vibrotactile stimulus consisting of a vertical trapezoid indentation ( $30 \mathrm{~g}$ force) provided by a 2 -mm-diameter probe attached to a force- and position-feedback controlled motor (Aurora Scientific, Aurora, Ontario, Canada) (cf. Chen et al., 2001, 2003; Friedman et al., 2004). During image acquisition, stimuli were presented to two different fingerpads. Thus, each block contained three stimulus conditions: two digits interleaved randomly with a no stimulus (blank) condition. The blank stimulus was as follows: (1) in vibrotactile blocks, the stimulus consisted of either mini motors attached to the fingerpads or the probe maintained at the baseline indentation of $3 \mathrm{~g}$; (2) in electrocutaneous stimulation, blocks consisted of no current being passed. Typically, only one stimulus type (vibrotactile 1, vibrotactile 2 , or electrocutaneous) was used per imaging session.

\section{Behavioral training}

Monkeys were first implanted with a head post and then trained to be quiescent in a primate chair. A felt body jacket and custom arm molds further secured the animal. Vet wrap and Velcro straps were used to secure the wrist, lower hand, and fingers. Drops of juice, raisins, and marshmallows were used as reinforcement. The animal was considered trained when the animal remained quiet in the chair for $>3 \mathrm{~h}$. Otherwise, the animal was not trained to perform on a behavioral task.

\section{Chamber maintenance}

After implantation of a head post and behavioral training, a craniotomy and durotomy were performed to expose the primary somatosensory cortex. A brief electrophysiological mapping procedure was used to locate the fingerpad region of Brodmann's areas $3 \mathrm{~b}$ and 1 . Monkeys were chronically implanted with a nylon chamber (16 $\mathrm{mm}$ diameter). Native dura was replaced with transparent artificial dura (Tecoflex; Thermedics Polymer Products, Wilmington, MA). With careful maintenance, this preparation allowed us to repeatedly image the same region of the cortex without infection or excessive dural growth for $>2$ years (Chen et al., 2002; Roe et al., 2002; Roe, 2004). Aseptic procedures were used at all times. Before opening the chamber, the outside of the chamber was first cleaned with an antiseptic solution. The chamber cap was then removed, and the inside was rinsed with sterile saline. Although in most instances removal of dural growth was unnecessary, a small amount of new dural growth emerges from between the artificial dural wall and the chamber wall. This growth has a gelatinous consistency and was easily removed with either forceps or cotton swabs. To help prevent infection, a sterile piece of gauze soaked in antibiotic was then placed in the chamber before closing the cap. Consistent implementation of these procedures prevented problems with dural growth and infection. In addition, the fluid contents of the chamber were tested intermittently for bacterial sensitivity, and antibiotics were chosen on the basis of this test.

\section{Anesthetized preparation}

After an initial preanesthetic dose of ketamine hydrochloride $(10 \mathrm{mg} / \mathrm{kg})$, atropine sulfate $(0.05 \mathrm{mg} / \mathrm{kg}$, i.m. $)$, and a light dose of diazepam $(0.25$ $\mathrm{mg} / \mathrm{kg}$, i.m.), anesthesia was maintained throughout the experiment with isoflurane $(0.8-1.5 \%)$. Animals were artificially ventilated to maintain an end-tidal $\mathrm{CO}_{2}$ of $4 \%$. Rectal temperature was maintained at $38^{\circ} \mathrm{C}$. Anesthetic depth was assessed by monitoring heart rate and EEG and by regular testing of reflexes and adjusted by minute adjustments of isoflurane. For stimulation, to position the hand and fingers palm side up, pegs imbedded in plasticine were glued to the fingernails.

\section{Awake preparation}

Before the imaging session, the animal was first lightly sedated with Acepromazine $(0.1-0.3 \mathrm{mg} / \mathrm{kg})$, diazepam $(0.1-0.2 \mathrm{mg} / \mathrm{kg})$, or ketamine $(2.5-5 \mathrm{mg} / \mathrm{kg})$ for chamber preparation and positioning of the imaging camera and fiber optic light guides. Chamber preparation included the application of agarose $(4 \%)$ and a silicone disc to immobilize the cortex and provide a transparent window for imaging. The setup procedure generally lasted $30 \mathrm{~min}$. During imaging, the animal's general behavior (e.g., eye position, alertness, body movements, etc.) was monitored through a digital video camera and video monitor placed outside the imaging room. In addition, heart rate, pulse oximetry, and rate of respiration were monitored. Generally, the animal became alert 30-40 min after initial sedation (as evidenced by eye and tail movements). Awake imaging sessions usually lasted $2.5 \mathrm{~h}$ with a collection of up to $96(48 \times 2)$ trials of each stimulus condition. Juice reward was given only during interstimulus intervals to minimize face and body movements related to licking during image acquisition.

Parallel stimulation conditions were used to compare cortical activations in the awake and anesthetized animal. Although identical stimuli were used, there are significant experimental differences between imaging in anesthetized and awake animals. In the anesthetized animal, imaging conditions are optimized to reduce motion and the physiological variability of the preparation, whereas in the awake animal, there is great variability in the respiration and heart rate of the animal and much greater motion artifact because of both body movements and to greater cortical pulsations. Differences also exist related to the stimulation. In the anesthetized monkey, the hand and fingers were positioned by pegs glued to the fingernails secured in plasticine. In the awake state, Velcro straps and vet wrap secured the lower hand and fingers. Because the animal is alert, there are occasional limb movements that may affect the imaged signal and lead to occasional trials with artifact and greater signal variability. Thus, because of physiological, mechanical, and behavioral factors, we found significant trial-to-trial variability of the optical signal in the awake animal. Despite this variability, consistent activations were sufficiently frequent that we could categorize activation patterns (compare Fig. 8) and sum across trials, to obtain consistent maps across trials and across imaging sessions spanning months of time.

\section{Optical imaging and analysis}

Image acquisition. Images were collected using the Imager 2001 and 3001 systems (Optical Imaging, Germantown, NY) and $630 \mathrm{~nm}$ illumination. A blood vessel map, used for landmark purposes, was collected with 570 $\mathrm{nm}$ illumination. In blocks of trials, stimuli were presented in a randomly interleaved manner. In a typical session with an anesthetized animal, 40-60 trials were collected per stimulus condition. For an awake animal, up to 96 repetitions of each stimulus condition were collected. Intrinsic signal maps were collected at five image frames per second for $3 \mathrm{~s}$ starting 
$200 \mathrm{~ms}$ before stimulus onset. Interstimulus intervals were $6-8 \mathrm{~s}$. The specific number of trials is indicated for each experiment in the corresponding figure legends.

Image analysis. Single condition maps indicate the response magnitude at each location in the image for a particular stimulus condition. The functional maps presented here are singlecondition maps obtained by subtracting the first prestimulus frame from each subsequent frame of the stimulus condition (first-frame subtracted). The blank condition is a $3 \mathrm{~s}$ series of images acquired during the no-stimulus condition. Such first-frame subtractions not only measure change from baseline but also reduce blood vessel artifact and minimize effects of uneven illumination. In single-condition maps, dark pixels indicate a response greater than that of the prestimulus image, and gray pixels indicate a response not different from the prestimulus image.

Because the fingerpad representation was located near the central sulcus, blood vessel artifact was at times substantial. Thus, we examined images frame by frame and block by block to remove trials or blocks that contained excessive noise. Instances of noise conditions included (1) images that were dominated by strong blood vessel noise, indicated by saturated optical signal (extreme black or white) around blood vessels, and (2) head or brain movement indicated by a lateral movement of the blood vessels. In addition, behavioral performance (e.g., body movements during imaging or wakefulness) was also used as a reference to exclude noisy images.

For awake data, each trial of raw images was visualized and classified into three categories consisting of area $3 \mathrm{~b}$ activation only, area 1 activation only, or area $3 \mathrm{~b}$ plus area 1 activation based on the signal distribution pattern across the expected activation locations. We considered pixels at the top $15 \%$ of pixel distribution as the activation regions.

Outlining activation hot spots. For each stimulus condition, image frames were summed to maximize the signal-to-noise ratio. A thresholding procedure was used to delineate the regions of strongest activation. Images were low-pass filtered (4 pixel rectangular kernel) and thresholded to identify pixels with strong activations. Some high-pass filtering was used to minimize effects of uneven illumination. Identical image processing parameters were used for all images acquired within each imaging session. To identify regions of strongest activation, singlecondition maps were thresholded at the top $15 \%$ of the gray pixel value distribution. We found that with different high- and low-pass thresholding criteria (10 and 25\%), the activation boundary shifted slightly, by only 8\% (cf. Vnek et al., 1999; Chen et al., 2003); thus, our conclusions were not dependent on the $15 \%$ threshold criteria.

Calculation of the size of activation. Once the hot spots of each activation were outlined by the thresholding method as described above, the total number of pixels outlined was calculated with the Scion (Frederick, $\mathrm{MD}$ ) program (personal computer version of NIH Image). Finally, the total pixel number was converted into square millimeters based on the image field of view.

Time-course analysis. The time course of reflectance change, during the period of image acquisition ( $3000 \mathrm{~ms}, 15$ frames including the prestimulus frame), was obtained over regions of activity in areas $3 \mathrm{~b}$ and 1 . Sample sizes measured $\sim 200 \mu \mathrm{m}$. Because absolute raw reflectance values vary significantly depending on lighting conditions and specifics of the preparation, we used the percentage of change in reflectance signal as a way of comparing across images and imaging sessions. The percentage of change from baseline was calculated by first-frame subtraction, in which the first $200 \mathrm{~ms}$ frame is subtracted from each of the subsequent $200 \mathrm{~ms}$ frames,
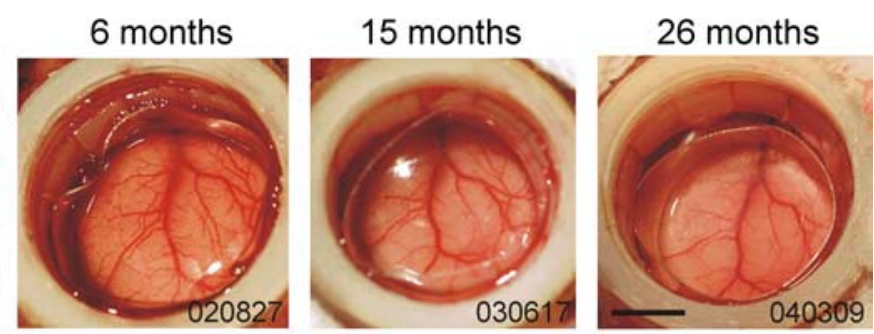

\section{Awake Anesthetized

 \\ $020426 \quad 020723$ \\ $020501 \quad 020801$ \\ $020503 \quad 020910$ \\ $020509 \quad 021016$ \\ $020514 \quad 030506$ \\ $020516 \quad 030617$ \\ $020521 \quad 030625$ \\ $020523 \quad 030703$ \\ $020814 \quad 030721$ \\ $020820 \quad 040309$ \\ $020823 \quad 040407$ \\ $020827 \quad 040415$ \\ $020830 \quad 040428$ \\ 040513}

Figure 1. Healthy cortex maintained during a 2 year period. $A$, Similarity of blood vessel maps during a 26 month period. Four time points are shown (day 0, 6 months, 15 months, and 26 months). $\boldsymbol{B}$, Electrophysiological mapping of areas $3 \mathrm{a}$, $3 \mathrm{~b}$, and 1 . The colored dots indicate electrode penetrations. Units in areas 1, 3b, and 3a are indicated by blue, green, and yellow dots, respec-

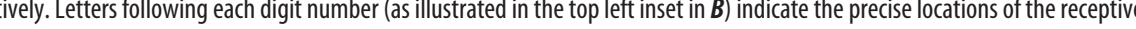
and 1. $\mathrm{mm} ; \boldsymbol{B}, 1 \mathrm{~mm}$. M, Medial; L, lateral; A, anterior; P, posterior.

$d R / R=100 \times((R s t i m(\mathrm{ti})-R(\mathrm{tff})) / R(\mathrm{tff}))$. The peak percentage of change in reflectance was used as a measure of peak signal amplitude. To further confirm that the reflectance change was indeed related to functional activation, control samples were also obtained from areas distant to the fingerpad region.

Statistical analysis. Statistical analyses were performed on the population of samples. Each sample from one region of activity was considered as one measurement within a map. ANOVA procedures and paired or unpaired $t$ tests were used to compare the effects of the independent variables (awake vs anesthetized, area $3 \mathrm{~b}$ vs area 1 ) on the dependent variables (peak signal amplitude and occurrence of different activation patterns). The criterion for significance for each statistical test was $p<$ 0.05 .

\section{Results}

Studies were conducted in two squirrel monkeys during a 2 year period. Although similar results were obtained from both monkeys, we present data primarily from one hemisphere of a single monkey because this permits meaningful comparisons of images collected at different time points and under anesthetized and awake states. Our comparisons are between awake and anesthetized activation patterns in SI (areas $3 b$ and 1) in response to single-digit stimulation.

The cortex remains healthy $>2$ years with a chronic chamber Chronic chambers were implanted over the somatosensory cortex in two squirrel monkeys. Figure $1 A$ illustrates that during a 26 month period, the appearance of the cortex remained clear and healthy $(0,6,15$, and 26 month time points shown). Note the consistency of the blood vessel patterns. The stability of the vascular patterns permitted the alignment of images over multiple optical imaging sessions. During this time period, we were able to 

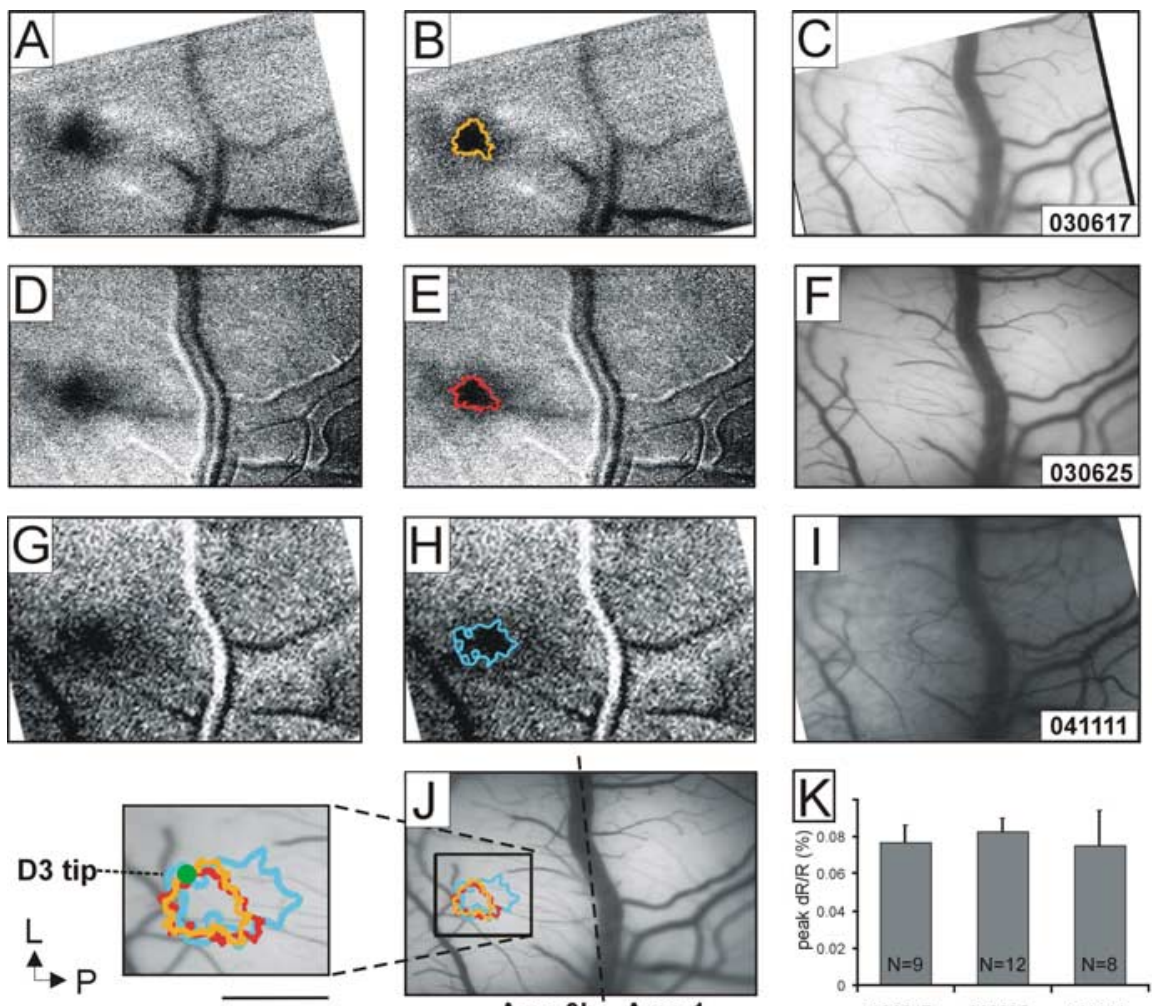

Area $3 b$ i Area 1

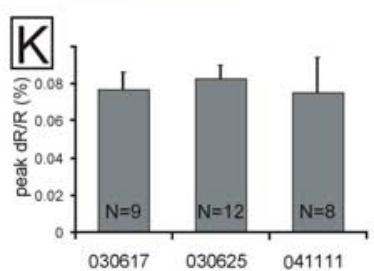

Figure 2. Stability of topographic maps over time in the anesthetized animal. $A, D, G$, First-frame-subtracted raw images to D3 indentation stimulation, aligned across three different imaging sessions. For each image, the clipping range is $\sim 0.2 \%$. Each image was clipped individually to \pm 2 SDs from its mean gray level. For the three imaging sessions in $A, D$, and $G$, signals were averaged from $45(n=9$ blocks), 60 ( $n=12$ blocks), and $40(n=8$ blocks) trials, respectively. $\boldsymbol{B}, \boldsymbol{E}, \boldsymbol{H}$, Color outlines derived from filtering and the thresholding method were overlaid on the raw images to indicate the location of greatest response. $C, F, I$, Corresponding blood vessel images from each day. J, Locations of activation indicated by color outlines were superimposed on the blood vessel map. The inset illustrates an expanded image of activation outlines and electrode penetration (green dot). The dashed line indicates the border between areas $3 \mathrm{~b}$ and $1 . K$, Absolute peak amplitudes of optical signal derived from three imaging sessions. L, Lateral; P, posterior. Scale bar, $1 \mathrm{~mm}$.

conduct $>29$ imaging experiments (15 awake, 14 anesthetized) (Fig. 1C) and obtain functional optical imaging maps from this cortex. Similarly, a series of brief electrophysiological mapping studies in the anesthetized animal was conducted to characterize the topography of the somatosensory cortex (areas 3a, 3b, and 1 in this field of view) and to examine its stability over time (Fig. $1 B)$. Area $3 \mathrm{~b}$ units were discriminated on the basis of small receptive field size (restricted to a single fingerpad), brisk responsiveness to light tapping, and a lateral to medial topography of digits D1-D5. Area 1 units typically have larger receptive fields covering more than one finger and respond best to stimuli stroked across the skin (Sur et al., 1982; Iwamura et al., 1993). Similar to units in area 1 , those in area 3 a also have larger receptive fields but preferentially respond to strong palpations and joint movement. Area $3 \mathrm{~b}$ was found anterior to the central sulcus (Fig. $1 B$, vertical dashed line) and was located posterior to area $3 a$ (Fig. $1 B$, slanted dashed line). Cortical representations of the distal fingerpads in area $3 \mathrm{~b}$ and area 1 (Fig. $1 \mathrm{~B}$, blue dots) were segregated by the representations of the middle phalanges and palm (Sur et al., 1982).

\section{Topographic maps over time in the anesthetized and awake animal}

Single-digit representation in the anesthetized cortex

Cortical responses during a period of 1.5 years was first examined in anesthetized animals. In one monkey, we repeatedly imaged time. the cortical response from areas $3 \mathrm{~b}$ and 1 (Fig. 2J, border between areas $3 \mathrm{~b}$ and 1 indicated by dashed line) in response to tactile indentation of a fingerpad. Images in response to stimulation of digit 3 (D3) from three different days $(2$ consecutive weeks and 1.5 years later) are shown in Figure $2, A, D$, and $G$, respectively. In the anesthetized animal, a prominent activation site is observed in area $3 \mathrm{~b}$. Consistent with previous reports (Tommerdahl et al., 1998, 1999, 2002; Chen et al., 2001, 2003; Friedman et al., 2004), activation in area 1 of the anesthetized animal is often weak or absent.

For each case, we delineated the strongest response region (using thresholding analysis described in Materials and Methods) with color outlines (Fig. 2B,E,H). The three images were then aligned using the blood vessel maps (Fig. 2C,F,I), and the outlines of the response regions were superimposed (Fig. $2 J$ ). As shown in Figure $2 J$, the somatotopic map was fairly stable during this period of time. There is a core of pixels that is activated in each of the 3 d. These pixels comprise $86,84.5$, and $53.5 \%$ of the activated sites in Figure 2, $A$, $D$, and $G$, respectively, and were consistent with repeated electrophysiological mapping sessions. These data indicate the topographic map of a distal fingerpad was stable for 1.5 years.

We also examined the stability of signal amplitude over time. The peak amplitudes of the optical signal (the percentage of change in peak reflectance; see Materials and Methods) obtained in three experiments are illustrated in Figure $2 \mathrm{~K}$. Although the absolute change in reflectance amplitudes for different imaging sessions differ because of factors such as the illumination level, the physiological stability of the animal, and anesthesia, the percentage of change in peak reflectance was relatively stable across experimental days. For the $3 \mathrm{~d}$ shown in Figure 2, the stimulus-induced activations in area $3 \mathrm{~b}$ fall in the $0.01-0.1 \%$ range $[0.077 \pm 0.01 \%(A), 0.083 \pm 0.007 \%(D)$, and $0.075 \pm 0.019 \%(G)$; no significant differences between each pair of days; all $t$ tests; $p>0.05$ ]. The signal amplitudes were consistent with the changes in reflectance reported previously in the anesthetized squirrel monkey (Tommerdahl et al., 1998, 1999, 2002; Chen et al., 2001, 2003; Friedman et al., 2004). Thus, signal amplitudes did not change appreciably from day to day or decline during the 2 year period.

In summary, we have demonstrated the ability to obtain images during a period of 2 years from the same region of the cortex. These images reveal, with respect to both location and amplitude of response, the basic stability of cortical maps in SI during that

Single-digit representation in the awake cortex

In the awake animal, we tested whether the representation of a distal fingerpad in areas $3 \mathrm{~b}$ and 1 was stable across days. Figure 3 shows images in response to vibrotactile stimulation of digit 4 obtained from three different days (Fig. $3 A, D, G$ ) in the same 
awake animal [field of view taken from the same region of the cortex as in Fig. 2; aligned penetration sites (green dots) and $3 \mathrm{~b} / 1$ border (dashed line) in Figs. $2 J$ and $3 J$ ]. Blood vessel maps (Fig. 3C, F, I) were used to align images across days. Both the location and signal amplitude of cortical responses were examined.

In contrast to the strong activation observed in area $3 \mathrm{~b}$ in the anesthetized state (Fig. 2), in the awake animal the strongest response was consistently obtained in area 1 , although at times, some activation is also observed in area $3 \mathrm{~b}$ (Fig. $3 D$, arrow). The activation in area 1 ranges from relatively focal (Fig. $3 A, D$ ) to fairly broad with diffuse boundaries (Fig. $3 G$ ). Despite this variability, a similar strongest response location (Fig. $3 \mathrm{~B}, E, H$, colored outlines) in area 1 is obtained across imaging sessions. As shown in Figure 3J, there is a core of pixels activated across each of the $3 \mathrm{~d}$ (the intersection of the red, yellow, and green outlines), the location of which is consistent with the electrophysiologically recorded site of D4 representation (green dot labeled D4). The ratio of this common core to each of the red (Fig. $3 A$ ), orange (Fig. $3 D$ ), and green (Fig. $3 G$ ) outlined areas is 16,11 , and $12 \%$, respectively. Two of these outlines (the red and orange outlines) are highly overlapped. The third (green) outline is shifted but still centered on the D4 representation. This shift is toward the representation of the proximal portion of the same finger, away from the distal fingertip (toward the area $1 / 3 \mathrm{~b}$ border) (Fig. $1 B$ ).

For comparison of anesthetized and awake activation sizes, the outline (blue) of the largest D3 activation in area $3 \mathrm{~b}$ in the anesthetized animal (as shown in Fig. 2 ) is overlaid in Figure 3J. Note that the activation in area 1 of the awake animal measures $\sim 2 \mathrm{~mm}$ across and is more than twice the size of activation in area $3 \mathrm{~b}$ in the anesthetized animal. Reflectance amplitudes were also larger in the awake animal. The peak amplitude of the optical signal across the different days is illustrated in Figure $3 \mathrm{~K}$. The percentage of change in peak reflectance remained robust over time. Compared with Figure 2, the signal amplitude obtained in the awake animal was several times greater than that obtained in the anesthetized animal, consistent with larger signal amplitudes recorded in the awake monkey visual cortex (Grinvald et al., 1991; Shtoyerman et al., 2000; Heider and Roe, 2002) and rat somatosensory cortex (Berwick et al., 2002). For the $3 \mathrm{~d}$ shown in Figure 3, peak amplitudes were $0.28 \pm 0.01 \%(A-C)$, $0.23 \pm 0.02 \%(D-F)$, and $0.26 \pm 0.06 \%(G-I)$. Signal amplitudes did not change appreciably from day to day ( $t$ test; $p>0.05)$.

Note that in addition to the overall shift in inter-areal activation, there is an absolute increase in activation in each of area $3 \mathrm{~b}$ and area 1 in the awake animal. That is, the average activation Figure 2.
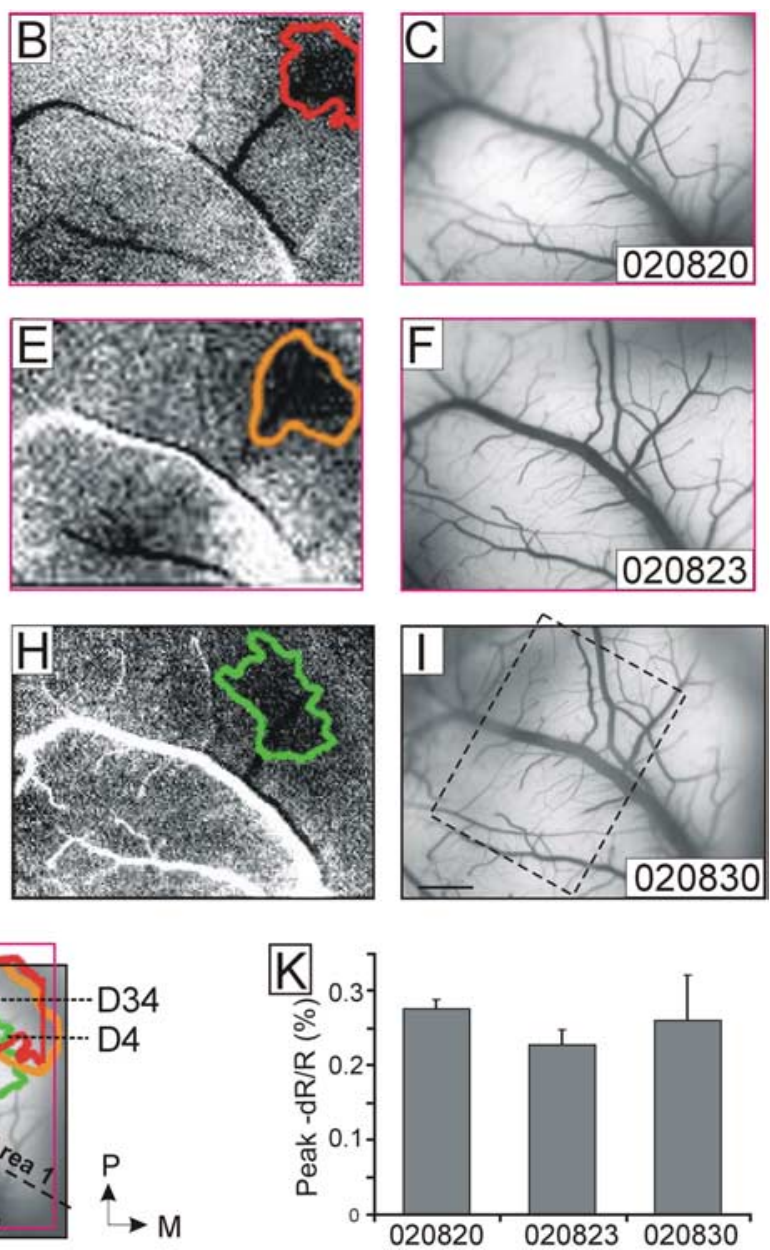

Figure 3. Stability of distal fingerpad representation in the awake animal. $\boldsymbol{A}, \boldsymbol{D}, \mathbf{G}$, First-frame-subtracted raw images to signals were averaged from 18 ( $n=9$ blocks), 24 ( $n=12$ blocks), and 16 ( $n=8$ blocks) trials, respectively. For each image, the rimposed on the blood vesselmap. Note the slightshift of the field of view hetween images in $A$ and $D$ and that in $G$ (indicated by red and black frames). For comparison, the location of D3 activation in the anesthetized condition (shown in Fig. 2) is also

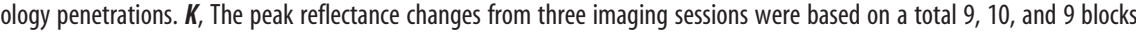
respectively. M, Middle; $P$, posterior. Scale bar: (in I) $\boldsymbol{A}-\boldsymbol{J}, 1 \mathrm{~mm}$. The dotted box in I indicates the position of the field of view in

amplitude of area $3 \mathrm{~b}$ in the anesthetized state (Fig. 2) is $0.078 \%$, whereas that in the awake state (Fig. 3 ) is $0.105 \%$. Similarly, in area 1 , the average activation amplitude in the anesthetized state (Fig. 2) is $0.03 \%$, whereas that in the awake state (Fig. 3 ) is $0.26 \%$. Thus, in absolute terms, activation amplitudes are greater in the awake than the anesthetized animal. However, the relative strengths of areal activations shift from area $3 b$ to area 1 in the awake animal.

In summary, in the awake animal (Fig. 3), the topography of maps across days was relatively stable and consistent with optical maps and with electrophysiological mapping obtained in the anesthetized state (Fig. 2). Furthermore, in the awake animal, signal size does not decline over time and is larger in area and in amplitude than that in the anesthetized animal.

Trial-to-trial activation in the awake animal

Typically, in optical imaging experiments, the signal-to-noise ratio is improved by summing across trials. This is a reasonable 
A Anesthetized
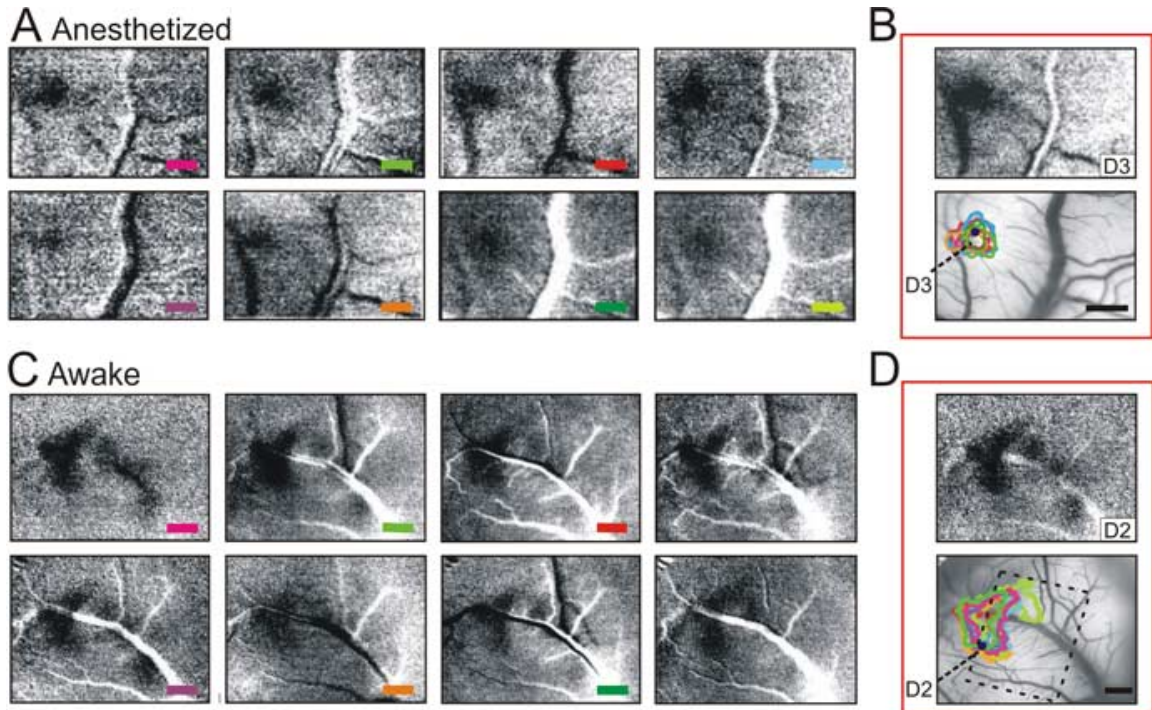

$\mathrm{D}$
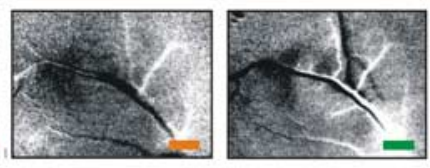

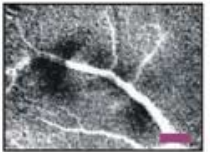

Figure 4. Consistency of trial-by-trial activation in the anesthetized and awake animal. $\boldsymbol{A}$, Eight individual trial images (first frame subtracted) taken from a single imaging session in the anesthetized animal in response to D3 indentation. Clip range, $\sim 0.1 \%$. B, Top, The summed image of eight trials. Bottom, Activations from each trial are outlined in color (corresponding image coded by color bars in $\boldsymbol{A}$ ) and superimposed on the blood vessel map. $\boldsymbol{C}$, Eight individual trial images taken from a single imaging session in an awake animal in response to D2 stimulation. Clip range, $\sim 2.0 \%$. D, Top, The summed image of these eight trials. Bottom, Activations from each trial are outlined in color (corresponding image coded by color bars in $\boldsymbol{C}$ ) and superimposed on the blood vessel map. The dotted box indicates field of view seen in $\boldsymbol{B}$. Consistency of signal location is indicated by the high degree of overlap of colored outlines. The green dots in $\boldsymbol{B}$ and $\boldsymbol{D}$ indicate electrophysiological recording sites. Each image was clipped individually to \pm 2 SDs from its mean gray level. Scale bars: $\boldsymbol{B}, \boldsymbol{D}, 1 \mathrm{~mm}$.

course of action only if there exists some degree of consistency from trial to trial. Therefore, we examined trial-to-trial variability in the awake animal compared with that in the anesthetized animal. Figure 4 illustrates two series of single trial images obtained in the same animal in the anesthetized $(A, B)$ and the awake $(C$, $D)$ states in response to identical vibrotactile stimulation of a single digit $[\mathrm{D} 3(A, B), \mathrm{D} 2(C, D)]$. Again, the same region of the cortex was recorded in both states (Fig. $4 D$, dotted box indicates field of view in $B$ ).

In the anesthetized animal, prominent activation in the D3 location in area $3 \mathrm{~b}$ is consistently observed in each of the eight trials shown (Fig. 4B, electrode recording site). There is little variation in activation location, as indicated by the overlapped color outlines (Fig. $4 \mathrm{~B}$, bottom). The sum of these eight trials is shown in Figure $4 B$ (top). The signal amplitude (0.027 \pm $0.004 \%)$ at the center of activation during the stimulation is significantly higher ( $p<0.001 ; t$ test $)$ than that during the nostimulus condition (data not shown; $0.004 \pm 0.004 \%$ ).

In the awake animal, there is consistently a prominent activation corresponding to the topographic location of D2 in both areas $3 \mathrm{~b}$ and 1 (Fig. $4 D$, electrode recording site in area $3 \mathrm{~b}$ ). The signal amplitude $(0.21 \pm 0.01 \%)$ at the center of activation during the stimulation is significantly higher $(p<0.05$; $t$ test $)$ than that during the no-stimulus condition (data not shown; $0.0096 \pm$ $0.0067 \%)$. However, in the awake animal, more variability is apparent. In addition to the topographically appropriate activation, other smaller and weaker activation zones also appear in some trials, perhaps because of occasional, although limited, volitional movements of other digits (Fig. 4C). Blood vessels are, in general, more prominent in the awake animal. Despite this greater variability in the awake animal, there is still a sufficient degree of consistency (Fig. 4D, overlapped outlines) that results in a strong activation zone at the topographically appropriate location in the summed image. The sum of these eight trials is shown in Figure
$4 D$ (top). Thus, consistent representation of a distal single fingerpad is obtained across trials within an imaging session in both the awake and anesthetized animal.

\section{Area $3 b$ versus area 1 dominance in the awake and anesthetized states}

We have already observed that anesthetized and awake activations differ in the relative activation of area $3 \mathrm{~b}$ versus area 1 . We now quantify these differences.

Time course and magnitude

Figure 5 illustrates the temporal development of the cortical response to D4 stimulation in the awake $(A)$ and anesthetized $(B)$ states to identical vibrotactile stimulation. In both the awake and anesthetized states, images are fairly flat when no stimulus is presented (Fig. $5 A, B$, bottom rows). Plots of the signal amplitude time course (Fig. 5C,D) illustrate three primary differences between the awake and anesthetized signals. First, comparison of the dominant activations show that the awake signal is maintained longer in area 1 (Fig. $5 C$, red time course), whereas the anesthetized signal in area $3 \mathrm{~b}$ declines after $2 \mathrm{~s}$ (Fig. 5D, black time course). Second, the signal magnitudes are several times greater in the awake animal (Fig. 5C,D, compare vertical scales). Third, in the anesthetized state, area $3 \mathrm{~b}$ activation magnitude is greater than that in area 1 (Fig. 5D, black greater than red), whereas in the awake state, area 1 activation magnitude is greater (Fig. $5 C$, red greater than black). Note that, in the awake state, there is also a short-lived and weaker activation in area $3 \mathrm{~b}$ (Fig. $5 C$, black line). As shown in Figure 5E, comparison of peak signal amplitudes in area $3 \mathrm{~b}$ (black) and in area 1 (red) reveals that, in the anesthetized state, area $3 \mathrm{~b}$ activation (peak amplitude, $0.11 \pm 0.02 \%$ ) is, on average, 1.6 times greater than that in area 1 (peak amplitude, $0.07 \pm 0.02 \%)$, whereas in the awake state, signal amplitude in area $1(0.27 \pm 0.09 \%)$ is 1.5 times greater than the signal in area $3 \mathrm{~b}(0.18 \pm 0.04 \%)$. Thus, although in the awake animal area $3 \mathrm{~b}$ activation is weaker than in area 1 , it is still greater than the activations in the anesthetized animal (Fig. 5E). As expected, control locations (regions far away from representation of the stimulated finger) remain relatively unmodulated (Fig. 5C,D, blue time courses, $E)(-0.03 \pm 0.03 \%$ in awake and $0.005 \pm 0.008 \%$ in anesthetized). This analysis suggests that in the awake state, the overall activation level across both areas $3 b$ and 1 is higher than that in anesthetized animal and that the inter-areal activation pattern (area 3b vs area 1) in the awake animal is shifted from area $3 \mathrm{~b}$ dominance to area 1 dominance.

To examine whether this areal shift is also observed with other types of tactile stimulation, in a second monkey trained to sit quietly, we used electrocutaneous tactile stimulation. We observed a similar shift in this monkey (Fig. 6). In this case, perhaps because of the stimulation paradigm, the signal is weaker and noisier, but a similar pattern emerges. As in the previous monkey, areas $3 \mathrm{~b}$ and 1 were mapped electrophysiologically to determine the area $3 \mathrm{~b} / 1$ border (Figs. $6 A, B$, dotted line in blood vessel maps). As shown in Figure $6 B$, electrocutaneous stimulation of digit $\mathrm{D} 2$ in the anesthetized monkey produces stronger activation 

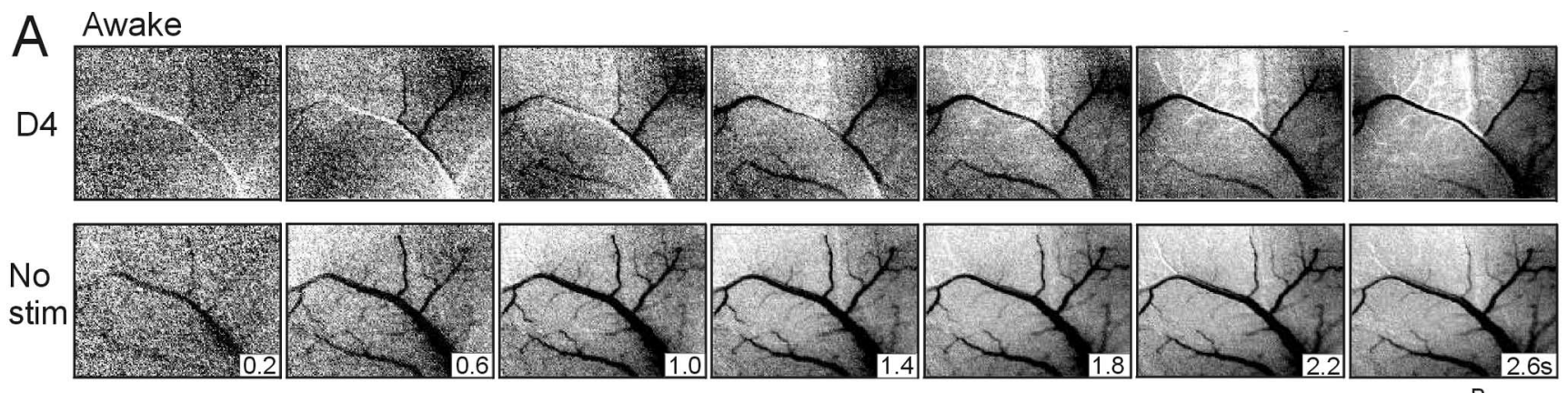

B Anaesthetized

D4
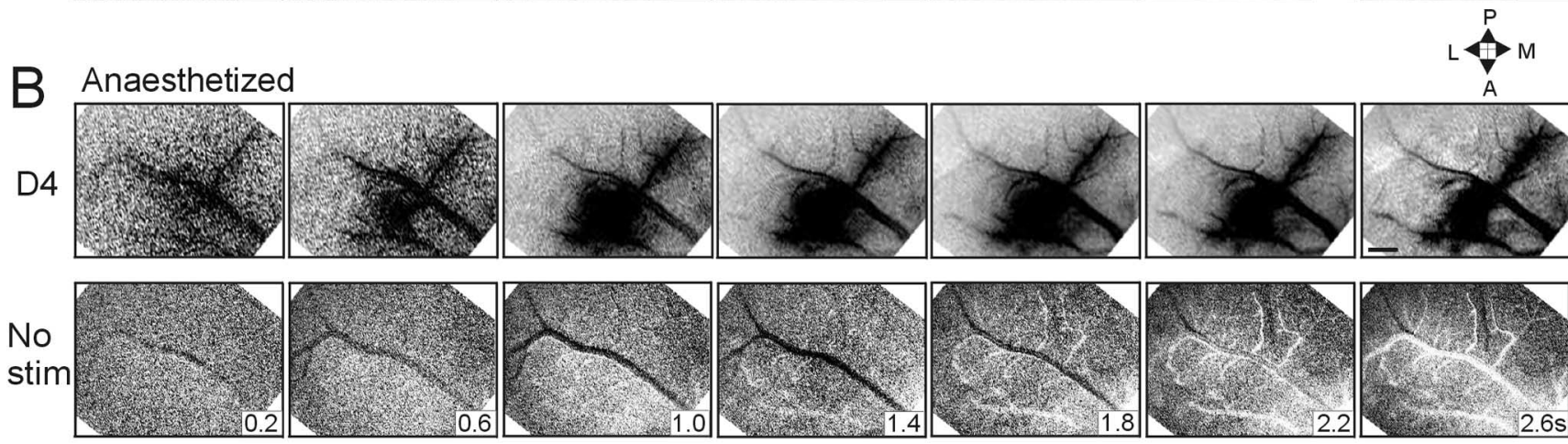

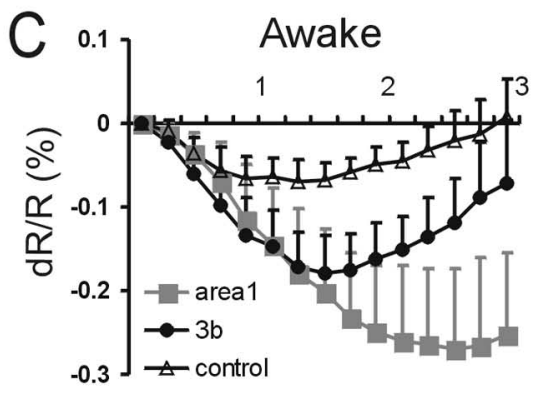

time (sec)

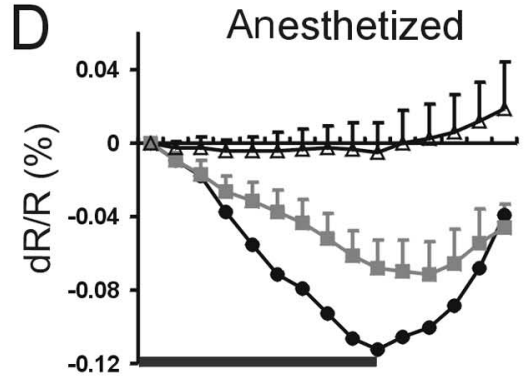

$-0.12$

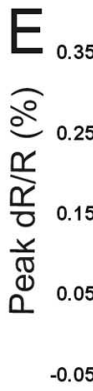

$\square$ area1 location

ab location

$\square$ control location

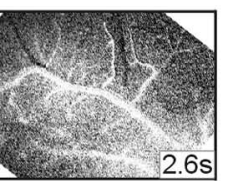

Figure 5. Temporal development of optical signal to identical vibrotactile stimuli on the same digit in both awake and anesthetized conditions in monkey 1. $\boldsymbol{A}, \boldsymbol{B}$, First-frame-subtracted raw images recorded to D4 vibrotactile stimulation in the awake ( $\boldsymbol{A}$, top row, sum of 18 trials) and anesthetized ( $\boldsymbol{B}$, top row, sum of 40 trials) states are shown. Images obtained in the no-stimulus ( No stim) condition are shown in the bottom rows. Poststimulus time points are indicated at the bottom right corner of each image. The clip range was $\sim 1.0 \%$ in the awake state and $0.2 \%$ in anesthetized state. $\boldsymbol{C}, \boldsymbol{D}$, Temporal profiles of the optical signal derived from the location of $\mathrm{D} 4$ activation in area $3 \mathrm{~b}$ (black line), area 1 (red line), and control (blue line) locations in the awake ( $\boldsymbol{C}$ and anesthetized $(\boldsymbol{D})$ states. The gray bar in $\boldsymbol{D}$ indicates the period of stimulus presentation. $\boldsymbol{E}$, Comparison of the absolute peak amplitude of response in area $3 \mathrm{~b}$ (black bar), area 1 (red bar), and control (blue bar) locations in awake (left) and anesthetized (right) animals. Error bars represent SE. Scale bar, $1 \mathrm{~mm}$. M, medial; L, lateral; A, anterior; P, posterior.

in area $3 \mathrm{~b}$ and weaker activation in area 1 . In the awake monkey, we imaged the same region (field of view in Fig. $6 \mathrm{~A}$ rotated to align with Fig. $6 B$; red box in $A$ and $B$ outlines approximately the same region). In the awake state (Fig. $6 A$ ), the more prominent activation is now seen in area 1 with relatively little activation evident in area $3 \mathrm{~b}$. These activations are not seen in conditions without stimulation (Fig. 6A, $B$, No stim). Consistent with the previous case, the signal time course peaks within the first $2-3 \mathrm{~s}$ and the signal magnitude $(0.17 \pm 0.02 \%)$ in the awake animal is several times larger than that in the anesthetized state $(0.023 \pm$ $0.0065 \%$; $p<0.001 ; t$ test $)$. In the no-stimulus conditions, the signal amplitudes are $0.029 \pm 0.017 \%$ in the awake animal and $-0.0073 \pm 0.008 \%$ in anesthetized state, respectively. These differences are quantified in Figure $6 \mathrm{E}$. Thus, under both types of tactile stimulation (vibrotactile and electrocutaneous), a shift in areal dominance from area $3 \mathrm{~b}$ in the anesthetized state to area 1 in the awake state is observed.

\section{Areal size of activation in the awake animal}

This relative dominance by area 1 in the awake state is also evident from the areal size of activations zones. As in Figures 2 and 3, activation sizes were determined by a thresholding and outlining procedure (see Materials and Methods). Outlined regions in area $3 \mathrm{~b}$ and area 1 were compared in 14 awake experimental sessions. In the awake state, significantly larger activations $(4.88 \pm 0.37$ $\left.\mathrm{mm}^{2}\right)$ are observed in area 1 than in area $3 \mathrm{~b}\left(3.09 \pm 0.3 \mathrm{~mm}^{2} ; t\right.$ test; $p<0.001)$. The data suggest that, in contrast to the anesthetized state in which larger activations occur in area $3 \mathrm{~b}$ than area 1 (see also Chen et al., 2001, 2003), in the awake state, activation in area 1 is larger in areal size as well as in amplitude.

\section{Greater variability in the awake animal}

Variability in areal activation patterns

Unlike the stable and consistent images collected in anesthetized animals, we observed more variability in activation patterns in 

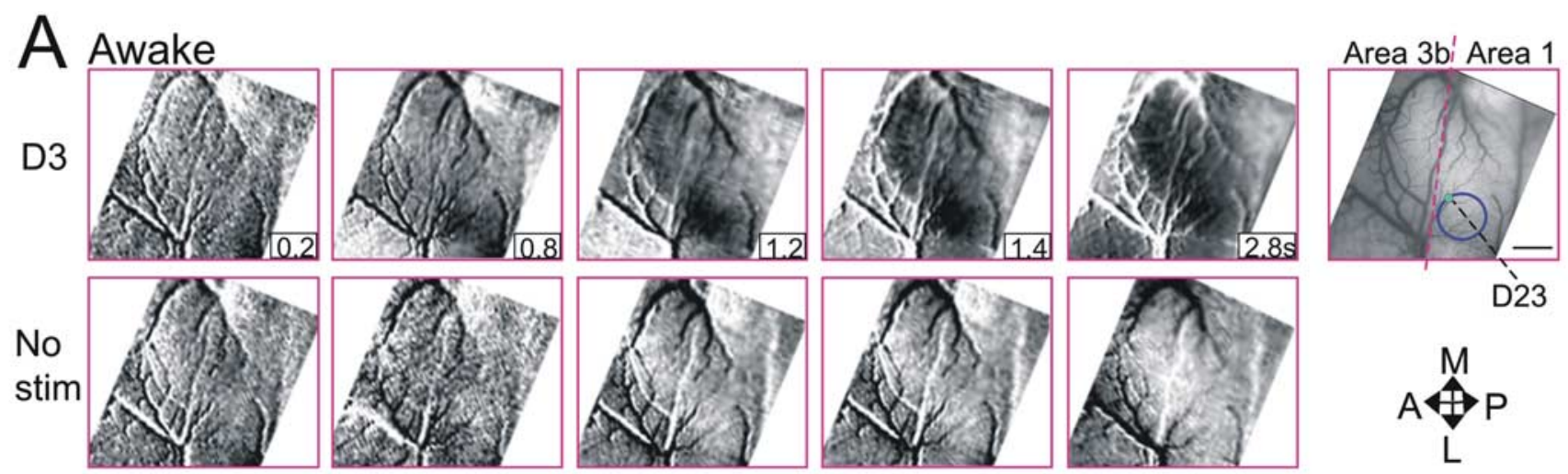

B Anesthetized
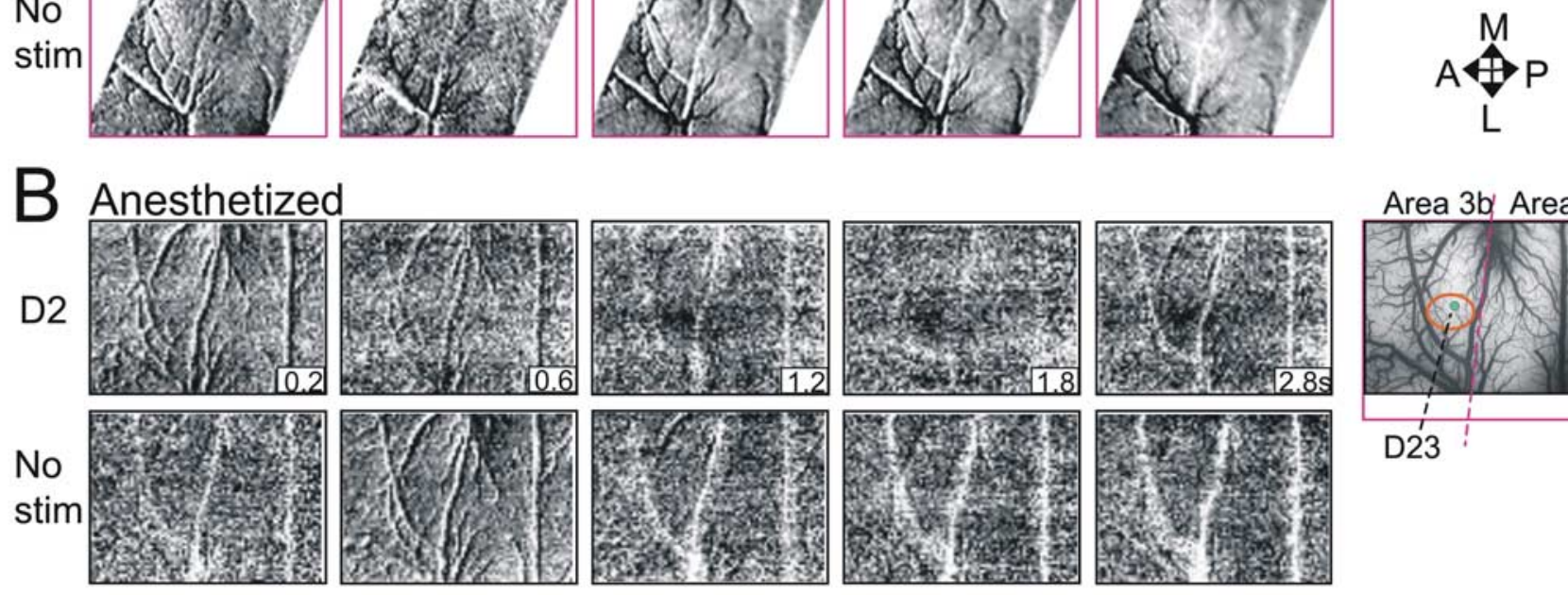

Area 3b Area 1
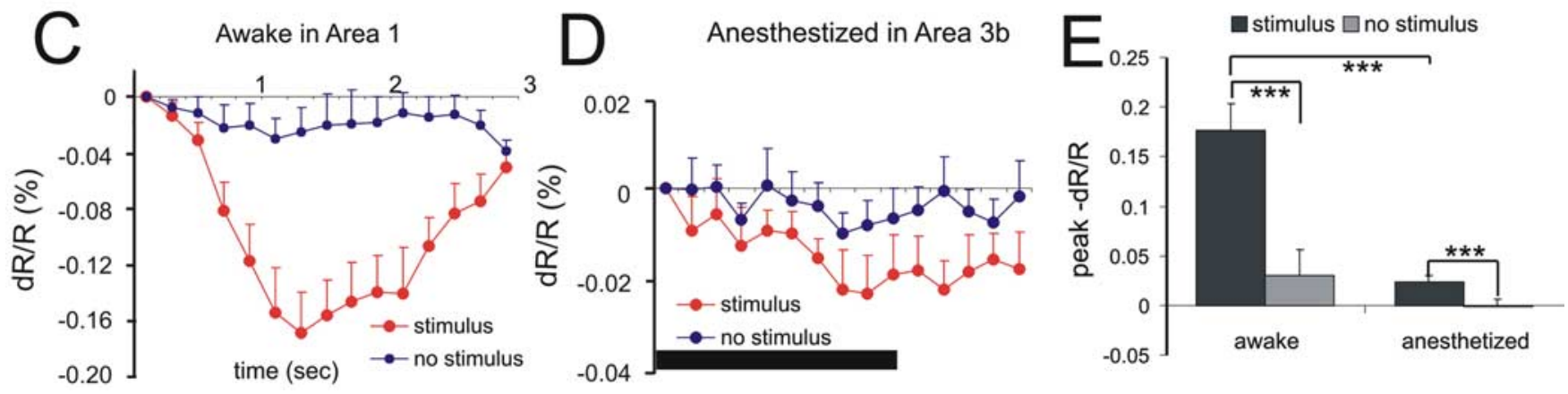

Figure 6. Temporal development of the optical signal in the awake $(\boldsymbol{A})$ and anesthetized $(\boldsymbol{B})$ conditions in response to electrocutaneous stimulation in monkey 2 . First-frame-subtracted raw images recorded to $D 3$ electrocutaneous stimulation in the awake state ( $\boldsymbol{A}$; top row, sum of 11 trials, $3.5 \mathrm{~mA}$ ) and to D2 electrocutaneous stimulation in the anesthetized state $(\boldsymbol{B}$; top row, sum of 12 trials, $5 \mathrm{~mA}$ ) are shown. Images obtained in the no-stimulus condition are shown in the bottom rows in $\boldsymbol{A}$ and $\boldsymbol{B}$. Image time point is indicated at the bottom right corner of each image (in seconds). The clip range was $\sim 0.5 \%$ in the awake state and $0.05 \%$ in the anesthetized state. Images in $\boldsymbol{A}$ are rotated to align with images in $\boldsymbol{B}$ (see blood vessel maps on the right). Scale bar, $1 \mathrm{~mm}$. No stim, No stimulus. Temporal profiles of $D 3$ stimulation in area 1 in the awake state $(\boldsymbol{C})$ and of D2 stimulation in area $3 \mathrm{~b}$ in the anesthetized state $(\boldsymbol{D})$ are shown. The red and dark blue lines in $\boldsymbol{C}$ and $\boldsymbol{D}$ represent the signal amplitudes in the stimulated and nonstimulated conditions, respectively. The gray bar in $\boldsymbol{D}$ indicates the period of stimulus presentation. $\boldsymbol{E}$, Comparison of the absolute peak amplitudes of response in the stimulus condition (black bars) versus no-stimulus condition (light gray bars) in awake (left) and anesthetized (right) states. ${ }^{* * *} p<0.001 ; t$ test. Error bars represent SE. Scale bar: A, $1 \mathrm{~mm}$. M, medial; L, lateral; A, anterior; P, posterior.

the awake state. Some of this variability is apparent in the location of activation within the digit representation (Fig. 3) or in the number and degree of locations activated (Fig. 4). In addition, we also observe greater variability in the patterns of cortical areal activation. In most of our anesthetized cases, we usually only observe one pattern of activation throughout the entire imaging runs within one experiment. For example, in the anesthetized animal, we typically obtain activation in area $3 \mathrm{~b}$ only; whenever activation in both areas $3 b$ and 1 is observed in the anesthetized animal, activation in area 1 is always weaker than that in area $3 \mathrm{~b}$. In contrast, within a single imaging session in an awake animal, we observe that area 1 activation is greater than area $3 \mathrm{~b}$ most of the time; however, at times we do see comparable area $3 \mathrm{~b}$ and area 1 activity and on occasion greater activation in area $3 \mathrm{~b}$ than area 1 .

To express how frequently these different patterns occur, we examined activation patterns in our nine best cases (Fig. 7A) and sorted all of the activations on a trial-by-trial basis into three categories: (1) area 3b activation substantially larger and/or stronger than area 1 ("area 3 b only"); (2) area 1 activation substantially larger and/or stronger than area 3b ("area 1 only"), and (3) comparable activation present in both areas $3 \mathrm{~b}$ and 1 ("areas $3 \mathrm{~b}$ and 1"). The occurrence of each activation pattern as a percentage of all trials was calculated for each imaging session. As shown in Figure $7 A$ (of nine sessions examined), the percentage of the area 1-only activation pattern is higher than the other two patterns. On average, in the awake animal, the percentage of trials showing area 1-only activation $(61 \pm 2 \%)$ is significantly higher than both area $3 b$-only activation $(23 \pm 3 \% ; p<0.001)$ and both areas $3 \mathrm{~b}$ and 1 activation $(16 \pm 2 \% ; p<0.001)$. The data further confirms that in the awake state, the higher-order area (area 1) exhibits stronger activation than the lower area (area 3b).

For comparison (Fig. 7B), we also examined a comparable 

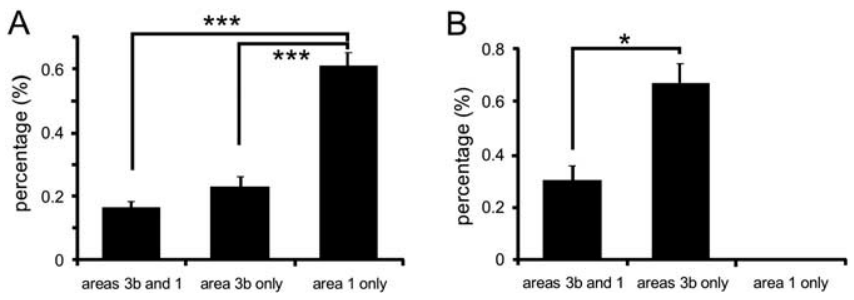

Figure 7. Dominance of area 1 activation in the awake animal. For the recording session of each day, we classified each block as area $3 \mathrm{~b}$ and 1 , area $3 \mathrm{~b}$ only, and area 1 only. The percentage of the area $3 \mathrm{~b}$ and 1 , area $3 \mathrm{~b}$-only, and area 1-only blocks were then calculated by dividing by the total number of blocks for that day. $A$, Average percentages of each activation pattern across nine cases in the awake state. $\boldsymbol{B}$, Average percentages of each activation pattern across nine cases in the anesthetized state. ${ }^{*} p<0.05 ;{ }^{* * *} p<0.001$.
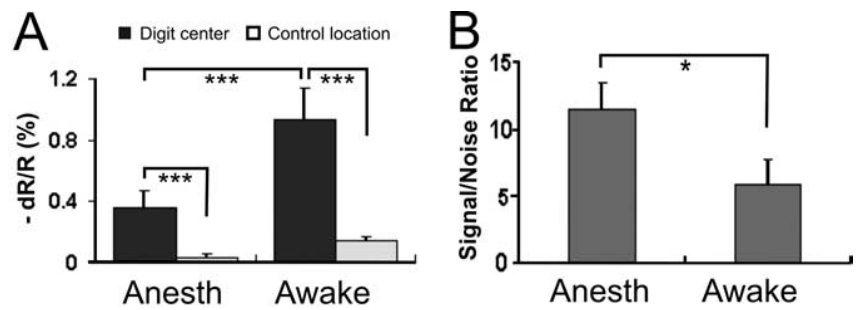

Figure 8. Signal-to-noise ratio in the anesthetized and awake states in monkey 1. A, Signal amplitudes at digit activation centers (signal; black bars) and at control locations (noise; gray bars) reveal that signal size and signal variability are larger in awake than in anesthetized animals. $\boldsymbol{B}$, This leads to a lower signal-to-noise ratio in the awake animal $(\sim 11.6$ in the anesthetized animal, 5.9 in the awake animal). Eleven and 13 blocks of images are averaged in the anesthetized (left column) and awake (right column) states, respectively. 0ptical signal amplitudes between digit centers and control locations in anesthetized $(p<0.001)$ and awake $(p<0.01)$ animals as well as between digit centers in anesthetized and awake animals ( $p<$ 0.01 ) were significantly different. ${ }^{*} p<0.1$; $^{* *} p<0.01$; $^{* * *} p<0.001$. Anesth, Anesthetized.

number of sessions in the anesthetized animal (nine sessions). Consistent with our qualitative impressions, the percentage of area $3 b$-only activation is significantly higher $(p<0.05)$ than the percentage of areas $3 \mathrm{~b}$ and 1 activation. Importantly, in no instance was area 1-only activation observed. Thus, there appear to be more variability in patterns of areal activation in the awake than in the anesthetized animal.

\section{Variability in signal amplitude: signal-to-noise ratio}

We also observed greater variability in signal amplitude in the awake animal. The peak signal amplitude was derived from the strongest activation region (from area $3 \mathrm{~b}$ in the anesthetized animal and from both areas 1 and $3 \mathrm{~b}$ in the awake animal). As shown in Figure $8 A$, the signal magnitude is two to three times larger in the awake than the anesthetized animal. However, both activated noise and baseline noise are greater in the awake animal. This is indicated by the larger error bars in signal amplitude at the digit center (awake: $0.94 \pm 0.21 \%, n=12$ sessions; anesthetized: $0.37 \pm 0.09 \%, n=13$ sessions) and nonstimulated (control) locations (awake: $0.16 \pm 0.03 \%, n=12$ sessions; anesthetized: $0.032 \pm 0.016 \%, n=13$ sessions). We wanted to examine whether this greater variability led to a reduced signal-to-noise ratio in the awake animal.

To calculate the signal-to-noise ratio, we divided the average stimulated amplitude by the average amplitude at the control location. The resulting signal-to-noise ratios in anesthetized and awake sessions are $\sim 11.6$ and 5.9 , respectively (Fig. $8 B$ ). This suggests that, under our recording conditions, the signal-to-noise ratio decreases by approximately one-half in the awake animal.
Thus, although signal magnitude is much greater in the awake animal, greater signal variability produces a lower signal-to-noise ratio.

\section{Discussion \\ Summary}

We have demonstrated the use of intrinsic signal optical imaging to study SI topography in awake squirrel monkeys and to compare awake signals to those in the same animal under anesthesia. In two awake squirrel monkeys, reflectance signal amplitudes and time courses were consistent in nature with cortical intrinsic signals observed under anesthesia. Responses to single distal fingerpad stimulation were repeatable from trial to trial within single sessions and over sessions spanning 2 years. We found that cortical topography of single fingerpads is comparable in the anesthetized and awake animal and stable over time. These results are not anesthesia specific, because in repeated imaging sessions under pentothal anesthesia, topography is also maintained (Chen et al., 2001, 2003).

Our three main results are as follows. In the awake animal, single-digit activations produced topographically appropriate but broader activation sizes, possibly but not necessarily suggesting cruder topography in the awake animal (see discussion below). Compared with signals obtained in the same animal under isoflurane anesthesia, the optical signal in the awake animal is several times larger both in areal size and signal amplitude, but, because of higher signal variability, signal-to-noise ratios are reduced in the awake animal. Finally, unlike the anesthetized animal in which area $3 \mathrm{~b}$ exhibits the greatest response, area 1 exhibits greater activation than area $3 \mathrm{~b}$ in the awake animal.

\section{Stability of cortical maps}

The representation of the body map in SI is not set in stone. Peripheral nerve transection or digit amputation leads to loss or decrease of cortical representation (Merzenich et al., 1983; Pons et al., 1988; Garraghty and Kaas, 1991; Schroeder et al., 1997), whereas increased or changed usage can lead to greater or otherwise reorganized cortical representation (Jenkins et al., 1990; Allard et al., 1991; Recanzone et al., 1992b; Polley et al., 2004). Intracortical microstimulation leads to an increased size of cortical representation (Recanzone et al., 1992a) with possible accompanying perceptual effects (Romo et al., 2000). Thus, cortical maps, even in the adult, are shaped by experience and provide an explanation for previously observed interindividual variability of cortical representation (Merzenich et al., 1987). In addition, a recent study indicated that the map in SI represents the location of perceived tactile stimulation rather than the location of physical stimulation on the skin (Chen et al., 2003). Together, these studies suggest that cortical maps are, even in the adult, shaped by experience and/or perceptual context. These possibilities provide additional impetus for developing cortical imaging methods in the awake animal.

In this study, we found that in the awake, untrained animal [consistent with previous studies in the rat (Chapin and Lin, 1984)], cortical representation of single fingerpads is essentially stable over time. The digit representation of passively stimulated hands was fairly stable over time and did not increase in the size of cortical representation (cf. Jenkins et al., 1990; Recanzone et al., 1992b). These data provide a baseline from which to interpret future optical imaging studies in awake, behaving animals. 


\section{Larger activation zones in awake animals: possible sources Not attributable to methodology}

We found that activations in response to single-digit stimulation in the awake state were two to three times larger in area than in the anesthetized state. It is possible that the larger activation size in the awake animal results from the summing of multiple focal activations, each with slightly shifted locations. We examined awake activations trial by trial and found that this is not the case. In the awake animal, both individual and summed trials have larger activation size than in the anesthetized animal. It is also unlikely that the larger activation area is caused purely by occasional body or limb movements, because these produce a distinct set of signal artifacts (e.g., excessive reflectance values, shifts of blood vessel patterns). Neither is the larger activation size as a result of thresholding differences between anesthetized and awake animals, because thresholds were calculated based on the pixel distribution of each image. Furthermore, this result is independent of the specific threshold level chosen; larger activations were obtained in the awake animal across multiple threshold levels. We have shown that, in absolute terms, activation amplitudes are greater in the awake than in the anesthetized animal. Although we have not done direct digit-to-digit comparison (i.e., D2 anesthetized/D2 awake), as shown in Figure 8 A, all digit activations in the awake animal are greater than all digit activations in the anesthetized animal (cf. Chen et al., 2001, 2003). Thus, we believe imaged activations in the awake animal are indeed larger in areal size than those in the anesthetized animal. However, there still remain significant differences (method of securing hands; variability in physiological, mechanical, and behavioral factors; and stimulus differences) between imaging conditions in the anesthetized and awake state. We cannot rule out at this point in time the possibility that these differences contribute to the anesthetized/awake differences.

\section{Subthreshold response}

The intrinsic optical signal has both spiking and subthreshold contributions. It has been shown that the subthreshold component can lead to larger area of activation than that evident from the spiking response (Hubel and Wiesel, 1974; Grinvald et al., 1994; Das and Gilbert, 1995; Toth et al., 1997; Schummers et al., 2002; Slovin et al., 2002; Series et al., 2003). If so, could the larger activation size in awake animals result from the greater subthreshold response in the awake state? One study suggests that this is not the case. In a study using voltage-sensitive dyes (an indicator that is biased toward revealing subthreshold activity), imaged activitation in the visual cortex in the awake animal was, in fact, relatively smaller than that in the anesthetized animal (Omer et al., 2004). It remains to be determined whether subthreshold activity is also lower in the awake versus anesthetized somatosensory cortex. If so, it would suggest that the larger activation size in awake animals is not attributable primarily to greater subthreshold activity.

\section{Receptive field dynamics}

A likely source of larger activation size is related to increases in the size and dynamics of receptive fields in awake animals. Both single-unit electrophysiology and 2-deoxyglucose studies (Juliano et al., 1981; McKenna et al., 1982) indicate that in the awake animal, representations of discrete regions on the skin can be found at many cortical locations, including locations outside that of the standard somatotopic maps (Sur et al., 1982). Large and dynamic receptive fields have been reported in SI of awake monkeys, especially in areas outside of area 3b (Iwamura et al., 1983). Additionally, stimulus context and attentional state are known to influence neuronal firing, neural signal-to-noise ratios, multiunit synchronicity, receptive field size, and tuning properties both in visual (Moran and Desimone, 1985; Das and Gilbert, 1995; Kapadia et al., 1999; Sharma et al., 2003) and somatosensory (Hsiao et al., 1993; Burton et al., 1997; Burton and Sinclair, 2000; Steinmetz et al., 2000; Meftah et al., 2002) neurons.

\section{Anesthesia}

The level of anesthesia is known to affect unit activity and receptive field size along the neural axis (McKenna et al., 1982; Armstrong-James and George, 1988; Yamamori et al., 1995; Friedberg et al., 1999). Differences have also been observed in optical images with differences in the level of anesthesia. Tommerdahl and Whitsel (1996) showed that an additional low dose of ketamine $(7.5 \mathrm{mg} / \mathrm{kg})$ dramatically reduced the signal size observed under halothane/nitrous anesthesia (although see Stryker et al., 1987). In general, the effects of anesthesia suggest that larger activation in the awake animal arises from an increase in excitability of afferent pathways and surround excitation, whereas under anesthesia, a smaller afferent drive and surround inhibition reduces the size of the amplitude and area of evoked activity.

\section{Larger activation zones in awake animals: implications for topography}

Larger activations may be related to cortical dynamics. In a study that compared recordings of cutaneous receptive fields in SI in anesthetized and chronically implanted, freely moving, awake rats, receptive fields were larger and more volatile than in the anesthetized animal (Chapin and Lin, 1984). However, they found that the general topography was not changed between anesthetized and awake rats. A number of studies in awake monkeys have described dynamic changes in somatosensory cortical receptive fields (such as increases in receptive field size, shifting "hot spots," or changes in spatial sensitivity profiles within receptive fields) or modulation of cortical activity with behavioral context (Nelson, 1987; Lee and Whitsel, 1992). Our imaging data are thus consistent with previous studies in awake monkeys and suggest that larger intrinsic signal activations reflect functional activities in the awake animal that are not present in the anesthetized animal. Image-guided electrophysiological investigation or studies with voltage-sensitive dyes, which enable tracking of fast changing events in awake monkeys, could provide additional understanding of this issue.

Surprisingly, in monkeys trained on frequency discrimination, cortical receptive fields become significantly larger, suggesting some correlation between increased receptive field size and behavioral discrimination (Recanzone et al., 1992b). Although the basis for this correlation is unknown, it could suggest that larger receptive field size reflects engagement of other intracortical circuits that would otherwise remain less active. Indeed, one study suggests that such discrimination training induces an additional cutaneous representation in area $3 \mathrm{a}$, one that displaces or dominates the normal deep receptor representation evident in area 3a (Recanzone et al., 1992c; cf. Schroeder et al., 1997). Thus, larger receptive field sizes (and by inference, larger imaged activation sizes) do not necessarily imply a "loss" of acuity or discriminability. Larger activation sizes could, in fact, indicate engagement of additional neural circuits not active in the anesthetized animal. Instead, nominal decrease in topographic precision, as measured either by receptive field size or imaged activation size, may indicate an increase in integration that accompanies 
context-dependent processes prevalent in awake monkeys (Recanzone et al., 1992c).

\section{Shift of areal dominance}

Numerous studies suggest a hierarchical relationship between areas 3b and 1 (Garraghty et al., 1990). However, relatively little is known regarding the relative activations of the different cortical areas within SI. In the anesthetized animal, we found that activation in area 1 is smaller in size and amplitude than that in area $3 \mathrm{~b}$. This result could be expected given the depressive effects of anesthetics on imaging higher-order and association areas, making those areas difficult to study in anesthetized animals; this provides additional motivation for developing methods for studying population response in awake, behaving animals [in monkey parietal cortex (cf. Siegel et al., 2003); in monkey prefrontal cortex (Siedemann et al., 2002; Roe, 2004); in rat barrel cortex (Berwick et al., 2002; Martin et al., 2002; Sachdev et al., 2003)]. In the awake animal, we found the activation ratio between areas $3 \mathrm{~b}$ and 1 reverses such that area 1 is dominant over area $3 b$. This suggests that not only the patterns of activation within each area, but the relative activation ratio between areas, play a role during sensory information processing (cf. Recanzone et al., 1992b; Mesulam, 1998; Roe, 2003). In the visual system, we have hypothesized a competition between a feedforward-dominated local feature ("real contour") detection system versus a feedback-dominated global feature ("illusory contour") detection system; the balance between these two systems determines the real or illusory perception (Ramsden, 2001; Roe, 2003; Dillenburger et al., 2004). Whether such shifts are related to attentional and behavioral context in the awake, behaving animal remains to be examined. Future experiments in awake animals will reveal possible commonalities in visual and somatosensory processing strategies (cf. Friedman et al., 2004).

\section{References}

Allard T, Clark SA, Jenkins WM, Merzenich MM (1991) Reorganization of somatosensory area $3 \mathrm{~b}$ representations in adult owl monkeys after digital syndactyly. J Neurophysiol 66:1048-1058.

Armstrong-James M, George MJ (1988) Influence of anesthesia on spontaneous activity and receptive field size of single units in rat $\mathrm{Sm} 1$ neocortex. Exp Neurol 99:369-387.

Berwick J, Martin C, Martindale J, Jones M, Johnston D, Zheng Y, Redgrave P, Mayhew J (2002) Hemodynamic response in the unanesthetized rat: intrinsic optical imaging and spectroscopy of the barrel cortex. J Cereb Blood Flow Metab 22:670-679.

Blankenburg F, Ruben J, Meyer R, Schwiemann J, Villringer A (2003) Evidence for a rostral-to-caudal somatotopic organization in human primary somatosensory cortex with mirror-reversal in areas $3 \mathrm{~b}$ and 1 . Cereb Cortex 9:987-993.

Burton H, Sinclair RJ (2000) Tactile-spatial and cross-modal attention effects in the primary somatosensory cortical areas $3 b$ and 1-2 of rhesus monkeys. Somatosens Mot Res 17:213-228.

Burton H, MacLeod AM, Videen TO, Raichle ME (1997) Multiple foci in parietal and frontal cortex activated by rubbing embossed grating patterns across fingerpads: a positron emission tomography study in humans. Cereb Cortex 7:3-17.

Carlson M (1981) Characteristics of sensory deficits following lesions of Brodmann's areas 1 and 2 in the postcentral gyrus of Macaca mulatta. Brain Res 204:424-430.

Chapin JK, Lin CS (1984) Mapping the body representation in the SI cortex of anesthetized and awake rats. J Comp Neurol 229:199-213.

Chen LM, Friedman RM, Ramsden BM, LaMotte RH, Roe AW (2001) Finescale organization of SI (area 3b) in the squirrel monkey revealed with intrinsic optical imaging. J Neurophysiol 86:3011-3029.

Chen LM, Heider B, Williams GV, Healy FL, Ramsden BM, Roe AW (2002) A chamber and artificial dura method for long-term optical imaging in the monkey. J Neurosci Methods 113:41-49.
Chen LM, Friedman RM, Roe AW (2003) Optical imaging of a tactile illusion in area $3 \mathrm{~b}$ of the primary somatosensory cortex. Science 302:881-885.

Costanzo RM, Gardner EP (1980) A quantitative analysis of repsonses of direction sensitivie neurons in somatosensory cortex of awake monkeys. J Neurophysiol 43:1319-1341.

Das A, Gilbert CD (1995) Long-range horizontal connections and their role in cortical reorganization revealed by optical recording of cat primary visual cortex. Nature 375:780-784.

Dillenburger B, Kwong IW, Roe AW (2004) Timing of illusory contour processing probed by real lines: support for V2-V1 feedback effects. Soc Neurosci Abstr 30:713.12.

Friedberg MH, Lee SM, Ebner FF (1999) Modulation of receptive field properties of thalamic somatosensory neurons by the depth of anesthesia. J Neurophysiol 81:2243-2252.

Friedman RM, Chen LM, Roe AW (2004) Modality maps within primate somatosensory cortex. Proc Natl Acad Sci USA 101:12724-12729.

Friston KL (1998) Imaging neuroscience: principles or maps? Proc Natl Acad Sci USA 95:796-802.

Garraghty PE, Kaas JH (1991) Large-scale functional reorganization in adult monkey cortex after peripheral nerve injury. Proc Natl Acad Sci USA 88:6976-6980.

Garraghty PE, Florence SL, Kaas JH (1990) Ablations of areas 3a and 3b of monkey somatosensory cortex abolish cutaneous responsivity in area 1 . Brain Res 528:165-169.

Grinvald A, Frostig RD, Siegel RM, Bartfeld E (1991) High-resolution optical imaging of functional brain architecture in the awake monkey. Proc Natl Acad Sci USA 88:11559-11563.

Grinvald A, Lieke EE, Frostig RD, Hildesheim R (1994) Cortical pointspread function and long-range lateral interactions revealed by real-time optical imaging of macaque monkey primary visual cortex. J Neurosci 14:2545-2568.

Heider B, Roe AW (2002) Time course analyses of intrinsic optical signals in anesthetized and awake macaque monkey visual cortex. Soc Neurosci Abstr 28:658.3.

Hsiao SS, Johnson KO, O'Shaughnessy DM (1993) Effects of selective attention of spatial form processing in monkey primary and secondary somatosensory cortex. J Neurophysiol 70:444-447.

Hubel DH, Wiesel TN (1974) Uniformity of monkey striate cortex: a parallel relationship between field size, scatter, and magnification factor. J Comp Neurol 158:295-305.

Hyvarinen J, Poranen A (1978) Movement-sensitive and direction and orientation-selective cutaneous receptive fields in the hand area of the post-central gyrus in monkeys. J Physiol (Lond) 283:523-537.

Iwamura Y, Tanaka M, Sakamoto M, Hikosaka O (1983) Converging patterns of finger representation and complex response properties of neurons in Area 1 of the first somatoensory cortex of the conscious monkey. Exp Brain Res 51:327-337.

Iwamura Y, Tanaka M, Sakamoto M, Hikosaka O (1993) Rostrocaudal gradients in the neuronal receptive field complexity in the finger region of the monkey's postcentral gyrus. Exp Brain Res 92:360-368.

Jenkins WM, Merzenich MM, Ochs MT, Allard T, Guic-Robles E (1990) Functional reorganization of primary somatosensory cortex in adult owl monkeys after behaviorally controlled tactile stimulation. J Neurophysiol 63:82-104.

Juliano SL, Hand PJ, Whitsel BL (1981) Patterns of increased metabolic activity in somatosensory cortex of monkeys Macaca fascicularis, subjected to controlled cutaneous stimulation: a 2-deoxyglucose study. J Neurophysiol 46:1260-1284.

Kapadia MK, Westheimer G, Gilbert CD (1999) Dynamics of spatial summation in primary visual cortex of alert monkeys. Proc Natl Acad Sci USA 96:12073-12078.

Lee CJ, Whitsel BL (1992) Mechanisms underlying somatosensory cortical dynamics: I. In vivo studies. Cereb Cortex 2:81-106.

Martin C, Berwick J, Johnston D, Zheng Y, Martindale J, Port M, Redgrave P, Mayhew J (2002) Optical imaging spectroscopy in the unanaesthetised rat. J Neurosci Methods 120:25-34.

McKenna TM, Whitsel BL, Dreyer DA (1982) Anterior parietal cortical topographic organization in macaque monkey: a reevaluation. J Neurophysiol 48:289-317.

Meftah el-M, Shenasa J, Chapman CE (2002) Effects of a cross-modal manipulation of attention on somatosensory cortical neuronal responses to tactile stimuli in the monkey. J Neurophysiol 88:3133-3149. 
Merzenich MM, Kaas JH, Wall JT, Sur M, Nelson RJ, Felleman DJ (1983) Progression of change following median nerve section in the cortical representation of the hand in areas $3 \mathrm{~b}$ and 1 in adult owl and squirrel monkeys. Neuroscience 10:639-665.

Merzenich MM, Nelson RJ, Kaas JH, Stryker MP, Jenkins WM, Zook JM, Cynader MS, Schoppmann A (1987) Variability in hand surface representations in Areas $3 \mathrm{~b}$ and 1 in adult owl and squirrel monkeys. J Comp Neurol 258:281-296.

Mesulam M-M (1998) From sensation to cognition. Brain 121:1013-1052.

Moran J, Desimone R (1985) Selective attention gates visual processing in the extrastriate cortex. Science 229:782-784.

Mountcastle VB, Powell TPS (1959) Neural mechanisms subserving cutaneous sensibility, with special reference to the role of afferent inhibition in sensory perception and discrimination. Bull Johns Hopkins Hosp 105:201-232.

Nelson RJ (1987) Activity of monkey primary somatosensory cortical neurons changes prior to active movement. Brain Res 406:402-407.

Nelson RJ, Sur M, Felleman DJ, Kaas JH (1980) Representations of the body surface in postcentral parietal cortex of Macaca fascicularis. J Comp Neurol 192:611-643.

Nelson RJ, Smith BN, Douglas VD (1991) Relationships between sensory responsiveness and premovement activity of quickly adapting neurons in areas $3 \mathrm{~b}$ and 1 of monkey primary somatosensory cortex. Exp Brain Res 84:75-90.

Omer DB, Slovin H, Grinvald A (2004) The dynamics of evoked and ongoing activity in the behaving monkey. Soc Neurosci Abstr 30:822.11.

Polley DB, Kvasnak E, Frostig RD (2004) Naturalistic experience transforms sensory maps in the adult cortex of caged animals. Nature 429:67-71.

Pons TP, Garraghty PE, Cusick CG, Kaas JH (1985) A sequential representation of the occiput, arm, forearm and hand across the rostrocaudal dimension of areas 1, 2 and 5 in macaque monkeys. Brain Res 335:350-353.

Pons TP, Wall JT, Garraghty PE, Cusick CG, Kaas JH (1987) Consistent features of the representation of the hand in area $3 \mathrm{~b}$ of macaque monkeys. Somatosens Res 4:309-331.

Pons TP, Garraghty PE, Mishkin M (1988) Lesion-induced plasticity in the second somatosensory cortex of adult macaques. Proc Natl Acad Sci USA 85:5279-5281.

Ramsden BM, Hung CP, Roe AW (2001) Real and illusory contour processing in area V1 of the primate: a cortical balancing act. Cereb Cortex 11:648-665.

Recanzone GH, Merzenich MM, Dinse HR (1992a) Expansion of the cortical representation of a specific skin field in primary somatosensory cortex by intracortical microstimulation. Cereb Cortex 2:181-196.

Recanzone GH, Merzenich MM, Jenkins WM, Grajski KA, Dinse HR (1992b) Topographic reorganization of the hand representation in cortical Area 3b of owl monkeys trained in a frequency discrimination task. J Neurophysiol 67:1031-1055.

Recanzone GH, Merzenich MM, Jenkins WM (1992c) Frequency discrimination training engaging a restricted skin surface results in an emergence of a cutaneous response zone in cortical Area 3a. J Neurophysiol 67:1057-1070.

Roe AW (2003) Modular complexity of Area V2 in the macaque monkey. In: The primate visual system (Collins C, Kaas J, eds), pp 109-138. New York: CRC.

Roe AW (2004) Long-term optical imaging of intrinsic signals in anesthetized and awake monkeys. In: Visualizing large-scale patterns of activity in the brain: optical and electrical signals (Buzsaki G, ed), pp 34-42. Washington, DC: Society for Neuroscience.

Roe AW, Healy FL, Friedman RM, Heider B, Chen LM (2002) Differences in SI topography between anesthetized and awake squirrel monkey as revealed by optical imaging. Soc Neurosci Abstr 28:651.3.

Romo R, Hernandez A, Zainos A, Brody CD, Lemus L (2000) Sensing without touching: psychophysical performance based on cortical microstimulation. Neuron 26:273-278.

Sachdev RN, Champney GC, Lee H, Price RR, Pickens III DR, Morgan VL, Stefansic JD, Melzer P, Ebner FF (2003) Experimental model for func- tional magnetic resonance imaging of somatic sensory cortex in the unanesthetized rat. NeuroImage 19:742-750.

Schroeder CE, Seto S, Garraghty PE (1997) Emergence of radial nerve dominance in median nerve cortex after median nerve transaction in adult squirrel monkey. J Neurophysiol 77:522-526.

Schummers J, Marino J, Sur M (2002) Synaptic integration by V1 neurons depends on location within the orientation map. Neuron 36:969-978.

Seidemann E, Arieli A, Grinvald A, Slovin H (2002) Dynamics of depolarization and hyperpolarization in the frontal cortex and saccade goal. Science 295:862-865.

Series P, Lorenceau J, Fregnac Y (2003) The "silent" surround of V1 receptive fields: theory and experiments. J Physiol (Paris) 97:453-474.

Sharma J, Dragoi V, Tennenbaum J, Miller EK, Sur M (2003) Modulation of $\mathrm{V} 1$ responses during acquisition of an internal representation of stimulus location. Science 300:1758-1763.

Shtoyerman E, Arieli A, Slovin H, Vanzetta I, Grinvald A (2000) Long-term optical imaging and spectroscopy reveal mechanisms underlying the intrinsic signal and stability of cortical maps in V1 of behaving monkeys. J Neurosci 20:8111-8121.

Siegel RM, Raffi M, Phinney RE, Turner JA, Jando G (2003) Functional architecture of eye position gain fields in visual association cortex of behaving monkey. J Neurophysiol 90:1279-1294.

Slovin H, Arieli A, Hildesheim R, Grinvald A (2002) Long-term voltagesensitive dye imaging reveals cortical dynamics in behaving monkeys. J Neurophysiol 88:3421-3438.

Steinmetz PN, Roy A, Fitzgerald PJ, Hsiao SS, Johnson KO, Niebur E (2000) Attention modulates synchronized neuronal firing in primate somatosensory cortex. Nature 404:187-190.

Stryker MP, Jenkins WM, Merzenich MM (1987) Anesthetic state does not affect the map of the hand representation within area $3 \mathrm{~b}$ somatosensory cortex in owl monkey. J Comp Neurol 258:297-303.

Sur M, Nelson RJ, Kaas JH (1982) Representations of the body surface in cortical areas $3 \mathrm{~b}$ and 1 of squirrel monkeys: comparisons with other primates. J Comp Neurol 211:177-192.

Sur M, Garraghty PE, Bruce C (1985) Somatosensory cortex in macaque monkeys: laminar differences in receptive field size in areas $3 b$ and 1 . Brain Res 342:391-395.

Tommerdahl M, Whitsel B (1996) Optical imaging of intrinsic signals in somatosensory cortex. In: Somesthesis and the neurobiology of the somatosensory cortex (Franzen O, Johansson R, Terenius L, eds), pp 369384. Basel: Birkhauser Verlag.

Tommerdahl M, Delemos KA, Favorov OV, Metz CB, Vierck CJ, Whitsel BL (1998) Response of anterior parietal cortex to different modes of samesite skin stimulation. J Neurophysiol 80:3272-3283.

Tommerdahl M, Delemos KA, Whitsel BL, Favorov OV, Metz CB (1999) Response of anterior parietal cortex to cutaneous flutter versus vibration. J Neurophysiol 82:16-33.

Tommerdahl M, Favorov O, Whitsel BL (2002) Optical imaging of intrinsic signals in somatosensory cortex. Behav Brain Res 135:83-91.

Toth LJ, Kim DS, Rao SC, Sur M (1997) Integration of local inputs in visual cortex. Cereb Cortex 7:703-710.

Ungerleider LG, Courtney SM, Haxby JV (1998) A neural system for working memory. Proc Natl Acad Sci USA 95:883-890.

Vnek N, Ramsden BM, Hung CP, Goldman-Rakic PS, Roe AW (1999) Optical imaging of functional domains in the cortex of the awake and behaving monkey. Proc Natl Acad Sci USA 96:4057-4060.

Wang X, Merzenich MM, Sameshima K, Jenkins WM (1995) Remodelling of hand representation in adult cortex determined by timing of tactile stimulation. Nature 378:71-75.

Woolsey CN, Marshall WH, Bard P (1942) Representation of cutaneous tactile sensibility in the cerebral cortex of the monkey as indicated evoked potentials. Bull Johns Hopkins Hosp 70:399-441.

Yamamori Y, Kishikawa K, Collins JG (1995) Halothane effects on lowthreshold receptive field size of rat spinal dorsal horn neurons appear to be independent of supraspinal modulatory systems. Brain Res 702:162168 . 